\title{
Retinoic Acid Signaling Identifies a Distinct Precursor Population in the Developing and Adult Forebrain
}

\author{
Gloria Thompson Haskell ${ }^{1,2}$ and Anthony-Samuel LaMantia ${ }^{1}$ \\ ${ }^{1}$ Department of Cell and Molecular Physiology and ${ }^{2}$ Curriculum in Neurobiology and University of North Carolina Neuroscience Center, University of North \\ Carolina at Chapel Hill School of Medicine, Chapel Hill, North Carolina 27599
}

\begin{abstract}
We asked whether retinoic acid (RA), an established transcriptional regulator in regenerating and developing tissues, acts directly on distinct cell classes in the mature or embryonic forebrain. We identified a subset of slowly dividing precursors in the adult subventricular zone (SVZ) that is transcriptionally activated by RA. Most of these cells express glial fibrillary acidic protein, a smaller subset expresses the epidermal growth factor receptor, a few are terminal deoxynucleotidyl transferase-mediated biotinylated UTP nick end labeling positive, and they can be mitotically labeled by sustained rather than acute bromodeoxyuridine exposure. RA activation in similar cells in SVZ-derived neurospheres depends on retinoid synthesis from the premetabolite retinol. The apparent influence of RA on precursors in vitro is consistent with key properties of RA activation in the SVZ; in neurospheres, altered retinoid signaling elicits neither cell death nor an acute increase in cell proliferation. There is apparent continuity of RA signaling in the forebrain throughout life. RA-activated, proliferative precursors with radial glial characteristics are found in the dorsal lateral ganglionic eminence and ventrolateral palliumembryonic rudiments of the SVZ. Thus, endogenous RA signaling distinguishes subsets of neural precursors with glial characteristics in a consistent region of the adult and developing forebrain.
\end{abstract}

Key words: forebrain; glia; neural precursor; olfactory bulb; subventricular zone; retinoic acid

\section{Introduction}

Retinoic acid (RA) signaling is required for olfactory pathway development and continues in the olfactory region as well as other forebrain regions throughout life (LaMantia et al., 1993, 2000; Anchan et al., 1997; Whitesides et al., 1998; Haskell et al., 2002). Nevertheless, the anatomical sites, cellular targets, and consequences of RA signaling in the forebrain remain obscure. These issues cannot be fully resolved by localizing retinoid receptors and cofactors or manipulating retinoid levels in vivo or in vitro (Rubin and LaMantia, 1999; Mic et al., 2004). Such approaches, while informative, cannot identify cells that respond to endogenous RA via signaling pathways, the activity of which is not significantly altered by acutely increased retinoid concentrations (for review, see Bastien and Rochette-Egly, 2004). To circumvent these difficulties, we evaluated endogenous RA signaling in adult and developing fore-

\footnotetext{
Received Feb. 4, 2005; revised June 10, 2005; accepted June 28, 2005

This work was supported by National Institute of Child Health and Human Development Grant HD029178 (A.S.L.) and minority supplement HD029178-10S1 (G.T.H.). The University of North Carolina (UNC) Neuroscience Center Expression Localization and Confocal Microscopy Cores were supported by National Institute of Neurological Disease and Stroke Grant NS031768. We thank T. M. Maynard for help with designing primers, creating graphics, and advice; Clifford Heindel for breeding mice and technical support; and E. Tucker and J. H. Councill for help with cell culture. Lance Brown also provided technical help. Y. Wu (UNC Neuroscience Center Expression Localization Core) performed the in situ localization experiments, and the Confocal Microscopy Core was used to generate the confocal images and quantitative analysis. We also thank H. T. Ghashgei, L. Pevny, and E. Anton for helpful discussions.

Correspondence should be addressed to Anthony-Samuel LaMantia, Department of Cell and Molecular Physiology, Campus Box \#7545, University of North Carolina at Chapel Hill School of Medicine, Chapel Hill, NC 27599-7545. E-mail: anthony_lamantia@med.unc.edu.

G. T. Haskell's present address: Department of Pharmacology and Cancer Biology, Duke University Medical Center, Durham, NC 27510.

DOI:10.1523/JNEUROSCI.0485-05.2005

Copyright $\odot 2005$ Society for Neuroscience $\quad$ 0270-6474/05/257636-12\$15.00/0
}

brain precursors or their neural and glial progeny using mice carrying an RA-responsive reporter transgene (Balkan et al., 1992; Colbert et al., 1993; Haskell et al., 2002).

Endogenous RA signaling in the forebrain may function as it does in the skin, lens, liver, lung, amphibian limbs, and deer antlers. At each site, RA influences regeneration or development by modulating gene expression in RA-responsive cells (LutzowHolm et al., 1992; Tsonis et al., 2000, 2002; Imai et al., 2001; Allen et al., 2002; Hind and Maden, 2004). RA may regulate comparable processes in olfactory bulb (OB) granule cells as well as adult or embryonic precursors that generate these interneurons throughout life (Doetsch et al., 1999a,b; Haskell et al., 2002; Stenman et al., 2003). Ventricles and associated tissues are significant RA sources (Herbert et al., 1986; Yamamoto et al., 1996; Smith et al., 2001), and retinoid synthetic enzymes, receptors, and cofactors are present in olfactory structures in the mature and developing forebrain (Krezel et al., 1999; Smith et al., 2001; Haskell et al., 2002; Yee and Rawson, 2005). Accordingly, we determined whether endogenous RA signaling distinguishes newly generated olfactory granule cells as well as molecularly defined precursors in the adult subventricular zone (SVZ) or its embryonic rudiments.

RA may influence survival, proliferation, or differentiation in distinct cell classes at specific forebrain sites from early development through adulthood. Altered RA signaling can reduce telencephalic size, influence neurogenic markers, disrupt cell migration, and alter complex behaviors, including learning and memory (Chiang et al., 1998; Denisenko-Nehrbass et al., 2000; Giardino et al., 2000; Smith et al., 2001; Wang et al., 2005). Despite many suggestive observations, there is little evidence that 
RA modulates these processes via specific actions on identified cell classes. Accordingly, we assessed the influence of RA on forebrain precursors in vivo and in vitro throughout life. Our results suggest that endogenous RA, via distinct metabolic and transcriptional pathways, regulates cell proliferation in a subset of slowly dividing astrocytes in the adult SVZ, as well as a subset of proliferative radial glia in a comparable region of the developing forebrain.

\section{Materials and Methods}

Animals. The Institutional Animal Care and Use Committee at the University of North Carolina at Chapel Hill reviewed and approved all animal experiments. Wild-type Institute of Cancer Research (ICR) mice as well as two independent lines of RA-sensitive transgenic (TG) mice on an ICR background (TG1 and TG2) were maintained by the University of North Carolina at Chapel Hill Department of Laboratory Animal Medicine. Timed pregnancies were generated by pairing ICR females with a homozygous transgenic male late in the day and defining embryonic day 0.5 (E0.5) the following morning, based on a vaginal plug. All animals used for immunocytochemical, in situ, or histochemical analyses were deeply anesthetized with urethane $(2 \mathrm{mg} / \mathrm{kg})$ before perfusion. For neurosphere preparation, animals were killed by rapid cervical dislocation before harvesting brain tissues.

Bromodeoxyuridine administration in vivo. To label newly generated neurons in adult mice [postnatal day 60 (P60)], bromodeoxyuridine (BrdU) (dissolved in $0.07 \mathrm{~N} \mathrm{NaOH}$ in $0.9 \% \mathrm{NaCl}$; Sigma, St. Louis, MO) was injected intraperitoneally at $75 \mathrm{mg} / \mathrm{kg}$ for $4 \mathrm{~d}$, and animals were perfused 3 weeks later $(n=3)$. To label earlier born granule cells, BrdU was injected once daily from $\mathrm{P} 0-\mathrm{P} 5$, and animals were perfused at P60 $(n=3)$. To label rapidly dividing SVZ cells, P60 animals received a single $\mathrm{BrdU}$ injection and were perfused $2.5 \mathrm{~h}$ later. To label resident precursors, $\mathrm{P} 60$ animals were given $\mathrm{BrdU}(10 \mathrm{mg} / \mathrm{ml})$ in their drinking water for 1 week and subsequently given regular drinking water for 1 month before they were killed ( $n=3$ TG1 and 3 TG2 mice).

Immunostaining and histochemistry. Brains from 3- to 6-month-old male TG mice, perfused with $2.5 \%$ paraformaldehyde in $0.1 \mathrm{M}$ sodium phosphate buffer, $\mathrm{pH} 7.4$, were cryoprotected in graded sucrose, embedded in agar-sucrose, and frozen in cryoembedding compound (OCT). Twenty micrometer cryosections were incubated with $0.2 \%$ BSA, $20 \%$ NGS, and $0.6 \%$ Triton X-100 in $0.1 \mathrm{M}$ PBS for $2 \mathrm{~h}$ before applying $1^{\circ}$ antibody in a similar solution with $0.3 \%$ Triton X-100 overnight. Alexaseries fluorescent $2^{\circ}$ antibodies were used (1:5000; Molecular Probes, Eugene, OR), and preparations were mounted in polyvinyl alcohol (Mowiol; Calbiochem, La Jolla, CA) with an anti-photobleaching compound (paraphenylene diamine). For BrdU detection, sections were first immunostained for other markers, incubated for $30 \mathrm{~min}$ in $2 \mathrm{~N} \mathrm{HCl}$ at $37^{\circ} \mathrm{C}$ followed by $0.1 \mathrm{M} \mathrm{NaBH}_{4}$, and stained with an anti-BrdU antibody. Terminal deoxynucleotidyl transferase-mediated biotinylated UTP nick end labeling (TUNEL) labeling (Roche Products, Hertfordshire, UK) was performed before immunostaining for $\beta$-galactosidase. Controls omitting either 1 or $2^{\circ}$ antibodies were performed for all markers (supplemental Table 1, available at www.jneurosci.org as supplemental material). Epifluorescent images were acquired on a Leica (Nussloch, Germany) Digital Microscopy Research microscope using Openlab software and were adjusted for contrast or size in Adobe Photoshop (Adobe Systems, San Jose, CA). For histochemical detection of $\beta$-galactosidase, E14.5 brains were immersion fixed ( $4 \mathrm{~h}$ at room temperature in $2.5 \%$ paraformaldehyde in $0.1 \mathrm{~m}$ phosphate buffer), vibratome-sectioned at $100 \mu \mathrm{m}$, and stained histochemically as described previously (Colbert et al., 1993). These sections were mounted in phosphate buffer and videoimaged on a Leica-Wild MZ420 photomacroscope.

In situ hybridization. In situ hybridization on adult and E13.5 brains fixed by perfusion (adult) or immersion (E13.5) with $4 \%$ paraformaldehyde in $0.1 \mathrm{M}$ phosphate buffer was performed on $15 \mu \mathrm{m}$ cryostat sections through the SVZ or ventral pallium/dorsal lateral ganglionic eminence (dLGE). Digoxygenin-labeled antisense probes were synthesized for retinoic acid receptor $\alpha(\operatorname{RAR} \alpha), \operatorname{RAR} \beta$ (Rubin and LaMantia, 1999), or retinaldehyde dehydrogenase 3 (RALDH3) (gift from P. McCafferey, E.
K. Shriver Research Institute, Waltham, MA). Hybridized sections were dehydrated, coverslipped, and videoimaged on a Leica DM IRB microscope.

Quantification. To estimate the percentage of RA-activated granule cells at P60 that were generated between P0 and P5 (the peak of initial granule cell genesis) (Hinds, 1968), we estimated the percentage of transgene/BrdU double-labeled cells compared with the total number of transgene-labeled cells in the granule cell layer of the P60 olfactory bulb. We counted cells in three systematically positioned fields at an initial magnification of $400 \times$ from the dorsal, middle, and ventral regions of the granule layer in four evenly spaced coronal sections from three P60 mice. Summed totals of all fields from individual animals were averaged to generate a percentage, with SEM representing variation among animals.

To analyze coexpression of multiple markers [i.e., transgene, GFAP, epidermal growth factor (EGF) receptor (EGFR), and BrdU], every transgene-labeled cell in three evenly spaced $20 \mu \mathrm{m}$ coronal sections through the anterior SVZ of three animals double-labeled for the transgene and each of the other markers was serially optically sectioned on a Zeiss (Thornwood, NY) LSM510 multiphoton confocal microscope (University of North Carolina Neuroscience Center Confocal Microscopy Core). The anteroposterior extent of the SVZ was defined by the rostral-most point of the genu of the corpus callosum (CC) and the initial appearance of the anterior commissure, respectively. Only sections that contained 10 or more transgene-labeled cells were analyzed, and our criterion for double labeling was colocalization in three or more consecutive $0.5 \mu \mathrm{m}$ optical sections. The sample fields included all transgenelabeled cells within $50 \mu \mathrm{m}$ of the lateral aspect of the lateral ventricle and $400 \mu \mathrm{m}$ of the ventricular surface of the dorsolateral arm of the SVZ. A total of 141 transgene-labeled cells were examined for GFAP expression, 152 were examined for EGFR, and 274 were examined for BrdU incorporation after long-term exposure. In addition, 133 long-term BrdUlabeled cells were examined for GFAP expression alone. We also counted the number of acutely BrdU-labeled SVZ cells that coexpress GFAP in three randomly selected $40 \times$ maximum projection images from three evenly spaced sections from three mice. A total of 385 acutely labeled BrdU cells were analyzed, and two independent observers reported similar percentages of double-labeled cells.

Embryonic and adult neurosphere cultures. For each adult neurosphere experiment, $\mathrm{SVZ}$ cells from a single animal were dissociated after $40 \mathrm{~min}$ of incubation $\left(37^{\circ} \mathrm{C}, 5 \% \mathrm{CO}_{2}\right)$ in trypsin, hyaluronidase, and DNase in Neurobasal-A (Invitrogen, San Diego, CA), 50 mm HEPES, $1 \times$ standard or retinol-free B-27 with N2 supplement (Invitrogen), $1 \times$ pen-strep, and $20 \mathrm{ng} / \mathrm{ml}$ recombinant human EGF/recombinant human basic FGF (Promega, Madison, WI). Cells were strained through a $40 \mu \mathrm{m}$ filter, spun, resuspended in $1 \mathrm{ml}$ of medium, and plated in 24-well dishes at 1000 cells/well. They were fed EGF and FGF every $3 \mathrm{~d}$, one-half of the media was exchanged on day 7 , and they were analyzed for gene, transgene, or protein expression on day 9 or 10 . To induce differentiation, neurospheres were placed on poly-lysine/laminin ( $5 \mu \mathrm{g} / \mathrm{ml}$; Roche)-coated chamber slides (Nunc, Naperville, IL) in media without EGF or FGF and supplemented with $1 \%$ fetal bovine serum. For whole-mount staining, undifferentiated primary neurospheres were placed onto coated chamber slides in growth media and were fixed and stained immediately after they had attached to the poly-lysine/laminin substrate (usually 3-4 h).

For embryonic neurospheres, ventricular/SVZ cells from the rostral forebrain of three E14.5 TG or ICR fetuses per experiment were dissociated after $15 \mathrm{~min}\left(37^{\circ} \mathrm{C} ; 5 \% \mathrm{CO}_{2}\right)$ in $1 \times$ trypsin and $10 \mu \mathrm{g} / \mathrm{ml}$ DNase in supplemented media consisting of DMEM/F-12 (Invitrogen) with $0.6 \%$ D-glucose, $1 \times$ pen-strep, $2.5 \mu \mathrm{g} / \mathrm{ml}$ insulin, $10 \mu \mathrm{g} / \mathrm{ml}$ transferrin, $2 \mathrm{nM}$ progesterone, $6 \mu \mathrm{m}$ putrescine, 3 nм selenium chloride, $2 \mathrm{~mm}$ glutamine (Sigma), and $1 \times$ B-27. Cells were strained, spun, resuspended as described above, and plated in six-well dishes at 5000/well. Cultures were fed on day 3 with $20 \mathrm{ng} / \mathrm{ml} \mathrm{EGF}$ and FGF. Some neurospheres were evaluated for transgene expression on day 5 or 6 , and others were differentiated and analyzed for neuronal or glial markers.

Transgene detection in living neurospheres. 5-Chloromethylfluorescein di- $\beta$-D-galactopyranoside (CMFDG) (100 $\mu \mathrm{m}$; Molecular Probes) was added to pooled neurospheres using brief hypotonic shock ( $90 \mathrm{~s}$ ). After this CMFDG exposure, cells were flooded with fresh growth media and 
incubated for $1 \mathrm{~h}$ before analyzing. The number of spheres containing at least one fluorescent cell was determined by viewing neurospheres live on an inverted Leica DM IRB microscope. All-trans RA and diethylaminobenzaldehyde (DEAB) (Sigma) were maintained as $10^{-2} \mathrm{M}$ stock in DMSO and diluted as indicated.

$B r d U$ labeling in vitro. Neurospheres were grown in control media as described above for 1 week. On day 8 , neurospheres derived from the same animal were exposed to either $10^{-6}$ or $10^{-7} \mathrm{M}$ all-trans RA, $10 \mathrm{~nm}$ DEAB, or $0.1 \%$ DMSO for $24 \mathrm{~h}$. Individual neurospheres were then placed, one per well, in coated chamber slides with fresh growth media containing 5 $\mu \mathrm{g} / \mathrm{ml}$ BrdU. Cultures were fixed $24 \mathrm{~h}$ later and stained for BrdU as described above. In the planar cultures that grew under these conditions, six fields (at an initial magnification of $400 \times$ ) were counted to obtain a mean ratio of BrdUlabeled cells. Four spheres were analyzed per condition, and the proportion of BrdU-labeled cells from three experiments was averaged (i.e., $n=12$ spheres for each condition). Each condition was compared with control using MannWhitney nonparametric statistical analysis.

Reverse transcription-PCR. Two independent RNA samples were extracted in Trizol (Invitrogen) from either grossly microdissected SVZ (two TG2 males) or 15-20 pooled primary TG2 neurospheres. Reverse transcription (RT) was performed using Promega reagents and random hexamers after DNase treatment (40 min). cDNA was diluted 1:3 and used as template for PCR (36 cycles). All primers (supplemental Table 2, available at www.jneurosci.org as supplemental material) were designed to span intron/ exon boundaries and were verified by amplicon sequencing as well as no-RT enzyme controls.

Live/dead assay on SVZ cells. Dissociated SVZ cells were cultured under neurospheregenerating conditions and plated in tissue culture-treated chamber slides (Nunc) at fivefold higher density. Each day, for $7 \mathrm{~d}$ after plating, Ethidium-D and calcein (Cell Viability kit; Molecular Probes) were added in PBS at a final concentration of 5 and $1 \mu \mathrm{M}$, respectively, and cultures were incubated at $37^{\circ} \mathrm{C}$ for $30 \mathrm{~min}$. For each experiment, the proportion of dead cells in nine fields (initial magnification, 400×) from two wells was averaged for each condition and time point.

\section{Results}

Transgene-labeled cells in the adult forebrain are not newly generated neurons

Transgene-labeled, presumably RA-activated, cells are prominent in the adult olfactory bulb and SVZ (Haskell et al., 2002). Thus, we first asked whether the DR5-RA response element (RARE) transgene distinguishes newly generated neurons. Transgene-labeled cells in the SVZ and OB granule cell layer do not express polysialylated neural cell adhesion molecule (PSANCAM) or doublecortin (Fig. $1 A, B$ ) (data not shown). There are occasional transgene-labeled cells in the rostral migratory stream (RMS); however, unlike migratory neuroblasts destined for the OB, they do not express PSA-NCAM (Fig. 1 B). To directly assess whether transgene-labeled cells in the $\mathrm{OB}$ are newly generated, we
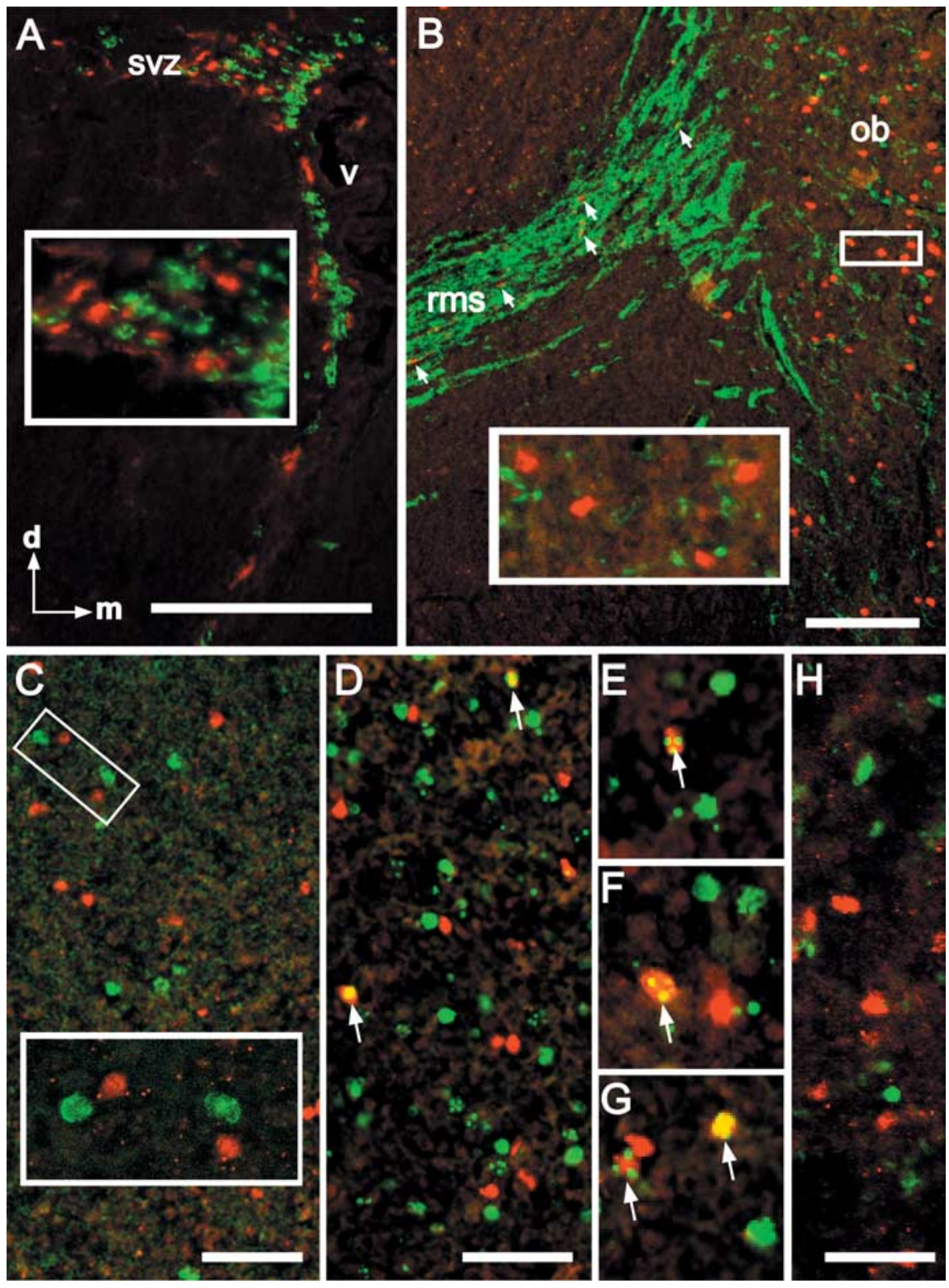

Figure 1. RA-activated cells in the SVZ and bulb are not newly generated neurons. $A$, Transgene-labeled cells (red; all panels) are distinct from PSA-NCAM-labeled cells (green) in the adult SVZ. Inset, Segregation of transgene and PSA-NCAM-labeled cells at higher magnification. $\boldsymbol{B}$, Transgene-labeled cells in the RMS (in the sagittal section) are occasionally interspersed with PSA-NCAMlabeled cells (arrows), but they do not appear to be PSA-NCAM labeled. In the OB granule cell layer, transgene and PSA-NCAMlabeled cells are also distinct. Inset, Segregation of individual transgene and PSA-NCAM-labeled cells in the OB. C, Transgene-labeled cells in the adult $O B$ are not BrdU positive (green) 3 weeks after $4 \mathrm{~d}$ of once-daily BrdU injections. Inset, Higher magnification of the boxed area in ( shows segregation of transgene and BrdU labeling. $\boldsymbol{D}$, BrdU-labeled, transgene-labeled cells (yellow) can be identified in the adult bulb after once-daily BrdU injections between P0 and P5 (arrows). $\boldsymbol{E}-\boldsymbol{G}$, Examples of transgene/BrdU double-labeled cells in the adult $0 B$ after early postnatal (P0 - P5) BrdU exposure (arrows). $\boldsymbol{H}$, Transgene-labeled cells are distinct from TUNEL-labeled cells (green) in the bulb at P10. Scale bars: $\boldsymbol{A}, \boldsymbol{B}, 100 \mu \mathrm{m} ; \boldsymbol{C}, \boldsymbol{D}, \boldsymbol{H}, 25 \mu \mathrm{m} ; \boldsymbol{E}-\boldsymbol{G}, 40 \mu \mathrm{m}$.

injected BrdU once daily for $4 \mathrm{~d}$ in adult TG mice and examined incorporation 3 weeks later. Despite many BrdU-labeled cells in the $\mathrm{OB}$, we did not detect any transgene/BrdU double-labeled cells in multiple serial sections from three transgenic mice (Fig. $1 C)$. Thus, although transgene-labeled cells are present in the adult SVZ and OB, the two populations are not directly related.

Our previous observations demonstrate that RA-activated cells in the mature bulb are GABAergic granule cells (Haskell et al., 2002). Thus, we next asked whether they might represent a relatively stable subset generated during early phases of postnatal granule cell genesis (Hinds, 1968). At P60, after once- 

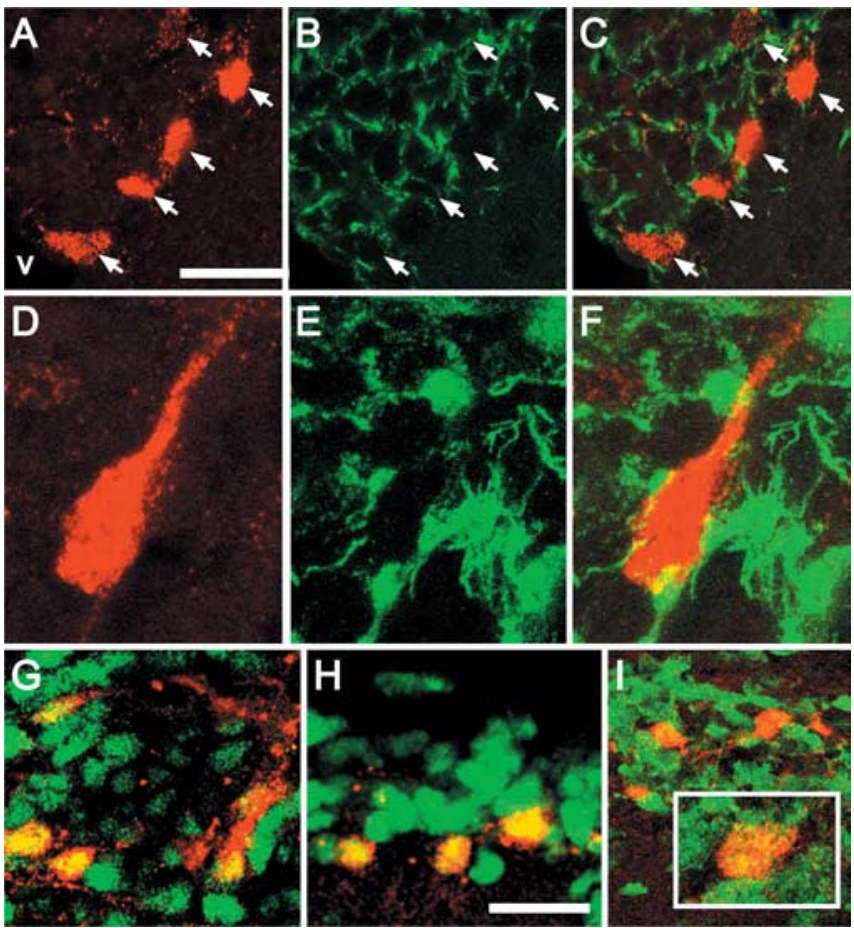

Figure 2. RA-activated SVZ cells express neural precursor and mitotic markers. $A, B$, Colorseparated images of five adjacent transgene-expressing cells ( $\boldsymbol{A}$, arrows) situated within a network of nestin-labeled processes ( $\boldsymbol{B}$, arrows) in a single optical section $(0.5 \mu \mathrm{m})$ through the $S V Z$, in a region adjacent to the ventricle (V). $C$, Merged image of $\boldsymbol{A}$ and $\boldsymbol{B}$ confirms coincidence of transgene and nestin labeling. $\boldsymbol{D}, \boldsymbol{E}$, Color-separated images of a fusiform transgene-labeled cell (D) with a single process oriented away from the ventricle seen within a network of nestinlabeled processes $(\boldsymbol{E})$. $\boldsymbol{F}$, Merged image of the single optical section in $\boldsymbol{D}$ and $\boldsymbol{E}$ shows that this cell, which has the morphology suggested for neural stem cells in the SVZ (Garcia et al., 2004) is double labeled for the transgene and nestin. G, A subset of Sox1-labeled SVZ cells (green) also expresses the transgene (red). $\boldsymbol{H}$, A subset of Sox2-labeled cells (green) also expresses the transgene (red). $I$, Transgene-labeled cells (red) express p27Kip 1 (green), which is more broadly expressed in the adult SVZ. Inset, An example of a single large transgene-labeled cell that also expresses p27Kip1. Scale bars: $\boldsymbol{A}-\boldsymbol{C}, 10 \mu \mathrm{m} ; \boldsymbol{G}, \boldsymbol{H}, 10 \mu \mathrm{m}$; width of images in $\boldsymbol{D}-\boldsymbol{F}, 10 \mu \mathrm{m}$.

daily BrdU injections between P0 and P5, 17.4\% of the transgene-labeled cells are also BrdU labeled (SEM, 1.25) (Fig. $1 D_{-}$ $G)$. Despite significant apoptosis in the bulb, particularly in the granule cell layer, during the first postnatal month (Fiske and Brunjes, 2001; Saito et al., 2004), transgene-labeled cells are distinct from TUNEL-positive cells at P10 (Fig. $1 \mathrm{H}$ ). Apparently, RA activation in the $\mathrm{OB}$ is associated with a relatively stable population of granule cells generated during early postnatal development.

\section{RA-activated SVZ cells express general markers of neural precursors}

To determine whether RA-activated cells in the SVZ are related to any class of adult neural precursors, we first examined coexpression of Nestin, Sox1, and Sox2, all of which are generally associated with neural precursor cells (Pevny and Rao, 2003). Nestin is colocalized in all transgene-labeled cells examined (Fig. 2A-C), including many large, fusiform cells with single processes oriented away from the ventricle (Fig. 2D-F). RA-activated cells comprise a subset of Sox1- and Sox2-positive cells in the SVZ (Fig. 2G,H). These cells also express p27Kip1 (Fig. 2I), an RAregulated modulator of cell proliferation associated with neural precursors as well as astrocytes in a variety of mitotic states (Dirks et al., 1997; Legrier et al., 2001; Nakatsuji and Miller, 2001;
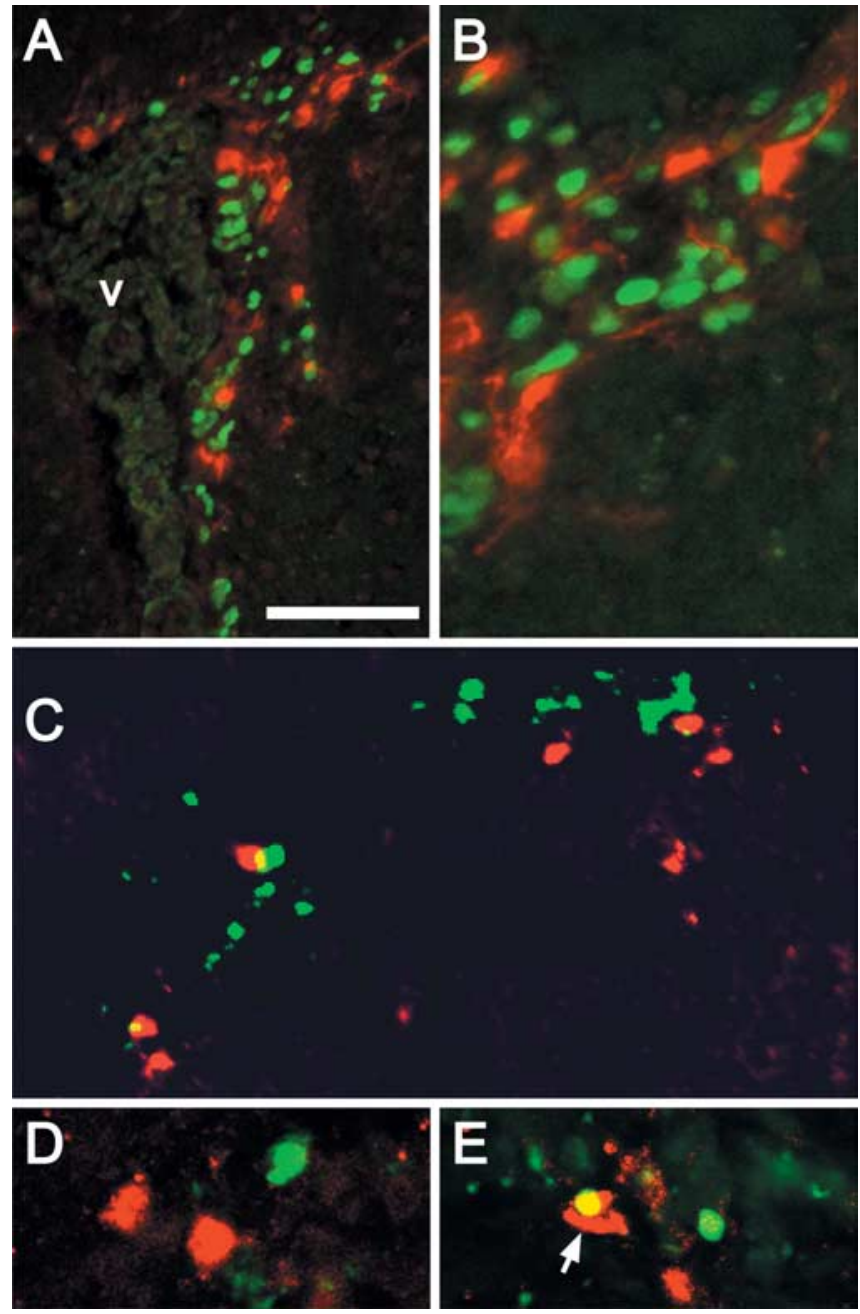

Figure 3. RA-activated cells in the SVZ are not transit-amplifying precursors or dying cells. $A$, Transgene-labeled cells (red) in the SVZ are not BrdU positive (green) $2.5 \mathrm{~h}$ after a single injection of BrdU. B, Higher-magnification image showing segregation of acute BrdU-labeled SVZ cells, which are more frequent, and transgene-labeled cells, which are slightly larger and occasionally have single processes oriented away from the ventricle. $\boldsymbol{C}, \boldsymbol{D}$, Transgene-labeled (red) and TUNEL-labeled (green) cells in the SVZ are primarily distinct populations. D, An occasional transgene/TUNEL-labeled cell can be identified by confocal microscopy in the SVZ (yellow; arrow). Scale bars: $\boldsymbol{A}, 50 \mu \mathrm{m} ; \boldsymbol{B}, 25 \mu \mathrm{m}$; width of image in $\boldsymbol{C}, 50 \mu \mathrm{m} ; \boldsymbol{D}, 40 \mu \mathrm{m}$.

Doetsch et al., 2002). The coincident expression of three characteristic markers (Nestin, Sox1, and Sox2) as well as an established RA-sensitive regulator of cell proliferation (p27Kip1) suggests that RA-activated cells in the SVZ are mitotically active precursors rather than recently postmitotic or differentiated neurons.

\section{RA-activated cells in the SVZ are not}

transit-amplifying precursors

To assess whether RA-activated precursors in the SVZ are rapidly dividing transit-amplifying cells (Morshead et al., 1994), we gave a single injection of BrdU to adult TG mice and assessed labeling $2.5 \mathrm{~h}$ later. The transgene-labeled population was not coincident with the acutely BrdU-labeled, presumed transit-amplifying SVZ population. Transgene-labeled cells are most prominent in the dorsolateral aspect of the SVZ and are apparently larger and less frequent than acutely labeled BrdU-positive cells (Fig. 3A,B). SVZ neurogenesis is accompanied by cell death among most transit-amplifying cells (Thomaidou et al., 1997; Morshead et al., 1998). Thus, we asked whether transgene-labeled SVZ cells are 
dying. TUNEL labeling indicates that these two populations are mostly distinct (Fig. $3 C$ ). When imaged confocally (Fig. $3 D, E$ ), only $7.6 \%$ of transgene-labeled SVZ cells were also TUNEL labeled (five doublelabeled cells in five sections each from two animals; $n=66$ transgene-labeled cells examined). Thus, RA-activated precursors have neither the proliferative nor apoptotic characteristics of transit-amplifying cells.

\section{RA-activated SVZ cells are astrocytes}

To evaluate whether DR5-RAREmediated RA signaling is associated with the other major class of SVZ precursors (resident slowly dividing astrocytes), we first examined transgene-labeled cells for expression of GFAP, a primary diagnostic marker for this population (Doetsch et al., 1999b; Morshead et al., 2003; Garcia et al., 2004). The majority of transgene-labeled SVZ cells $(87 \%)$ express GFAP (Fig. 4A$G)$, and an additional $9 \%$ were ambiguously associated with fibrillary GFAP immunoreactivity. Some of these cells have the fusiform morphology and single process associated with SVZ precursors (Garcia et al., 2004) (Fig. 4B, G). A small percentage of transgene-labeled cells do not express GFAP (4\%); however, they are adjacent to transgene/GFAP-labeled cells (Fig. $4 B$, arrow). Finally, transgene/ GFAP-labeled cells frequently contact blood vessels (Fig. 4A, inset, $G, K$ ). Thus, the transgene-labeled cells have multiple characteristics associated with astrocytes thought to constitute a distinct class of SVZ precursors.

The EGFR labels a subset of GFAPpositive cells as well as the majority of transit-amplifying precursors in the SVZ (Doetsch et al., 2002). We found that 23\% of transgene-labeled cells express EGFR (Fig. $4 H$ ). Cage-like networks of small EGFR-expressing cells often surround large transgene-labeled cells (Fig. $4 H$, inset), and orthogonal confocal projections indicate that such transgene-labeled cells do not express EGFR (Fig. 4I). Most transgene-labeled cells are completely distinct from EGFR-expressing cells (Fig. $4 J$ ); however, they are sometimes intercalated between EGFR-expressing cells (Fig. $4 \mathrm{~K}$ ).

The smaller population of transgene/EGFR-labeled cells frequently appears as "doublets" (two adjacent cells) in close contact with the ventricle of the dorsolateral arm of the SVZ (Fig. $4 \mathrm{~L}$ ). Together, the unique quantitative signature of GFAP and EGFR expression suggests that the RA-activated population constitutes a distinct subclass of neural precursors (see Fig. 9A).

\section{RA-activated cells are slowly dividing precursors}

It has been suggested that resident GFAP-expressing neural precursors in the SVZ divide slowly with a cell cycle time of up to $12 \mathrm{~d}$
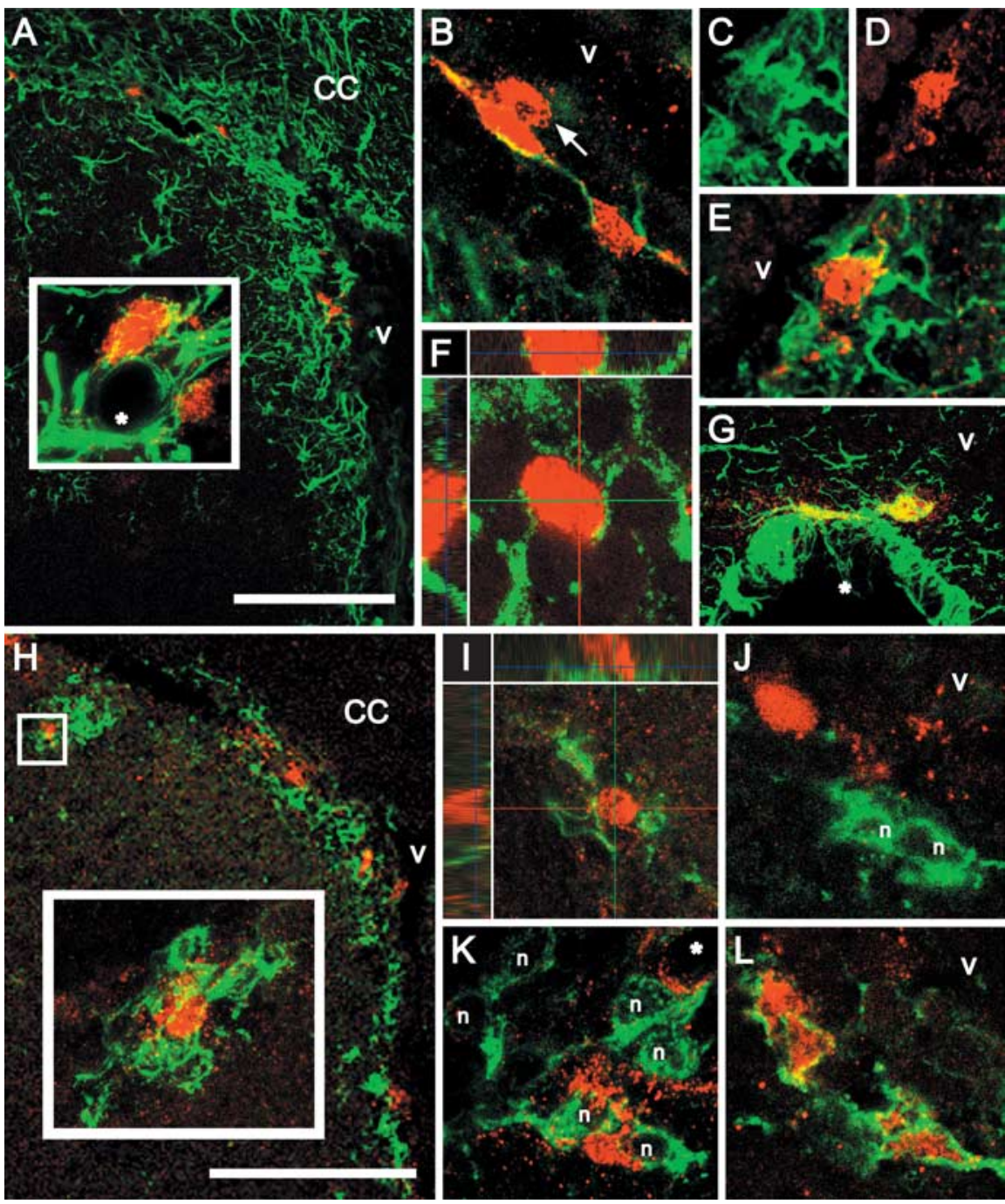

Figure 4. Most transgene-labeled cells are GFAP-labeled astrocytes. $\boldsymbol{A}$, Several transgene-labeled cells (red) are seen within a network of GFAP-labeled cells and processes (green) in the SVZ. The CC indicates orientation of this coronal section. Inset, A transgene-positive cell that also expresses GFAP (yellow) contacts an apparent blood vessel (asterisk). $\boldsymbol{B}$, Two transgene/GFAP double-labeled cells are near or immediately adjacent to a cell labeled for the transgene only (arrow). C, D, Color-separated images of a transgene/GFAP-labeled cell immediately adjacent to the lateral ventricle. $\boldsymbol{E}$, Merged image confirms coincidence of GFAP and the transgene in this cell. $\boldsymbol{F}$, Orthogonal views (indicated by green and blue lines) of a single $0.3 \mathrm{~mm}$ optical section demonstrates a transgene-positive nucleus surrounded by a GFAP-positive perinuclear ring and intimately associated with GFAP-labeled processes. G, A transgene-labeled, fusiform cell with a single long process, also labeled by GFAP, contacts a prominent blood vessel (2terisk) in the SVZ. $\boldsymbol{H}$, Low-magnification image shows transgene-labeled (red) and EGFR-labeled cells (green) in a coronal section of the SVZ. Inset, An individual transgene-labeled cell surrounded by a network of EGFR-labeled cells indicates potential ambiguity in detecting double labeling. $\boldsymbol{I}$, Orthogonal views of a single optical section from the inset in $\boldsymbol{H}$ indicate that this transgene-labeled cell does not express EGFR. J, A single-labeled, large, fusiform transgene-expressing cell is adjacent to two EGFR-labeled cells ( $\mathrm{n}$ ). $\boldsymbol{K}$, A transgene-labeled cell and its processes intercalated between EGFR-expressing cells (nuclei labeled n). In this image, transgene-labeled processes apparently contact a blood vessel (asterisk), whereas those of the EGFR-expressing cells do not. $L$, Doublets of transgene-labeled cells that also express EGFR (green) in this unequivocal example of transgene/EGFRlabeled cells in a single optical section through the SVZ. Scale bars: $\boldsymbol{A}, \boldsymbol{H}, 100 \mu \mathrm{m}$; width of images in $\boldsymbol{B}, \boldsymbol{E}-\boldsymbol{K}, 40 \mu \mathrm{m} ; \boldsymbol{J}, 35 \mu \mathrm{m}$.

(Morshead et al., 1994). Thus, we asked whether RA-activated cells could incorporate BrdU and remain in the SVZ 1 month after longterm exposure, a protocol used to identify slowly cycling resident precursors in other tissues, including the nervous system (Bickenbach and Chism, 1998; Otteson et al., 2001). Thirteen percent of transgene-labeled cells from TG1 mice incorporated BrdU and remained in the SVZ (Fig. 5A-D), and a similar percentage (15\%) was seen in the independent TG2 line. To confirm that this schedule of BrdU exposure and survival identifies primarily slowly dividing precursors, we evaluated the frequency of GFAP expression in long- 

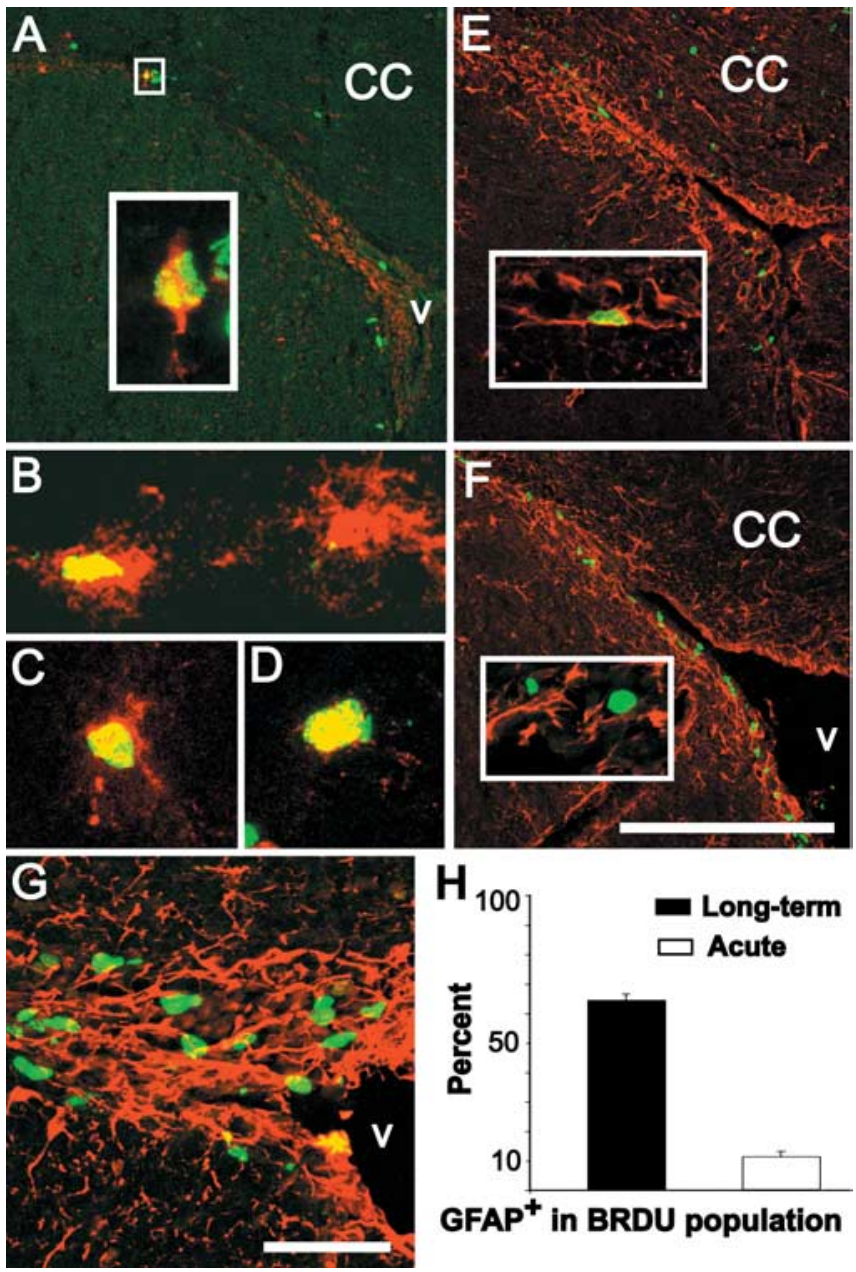

Figure 5. RA-activated cells in the SVZ are a subset of resident, slowly dividing precursors. $\boldsymbol{A}$, Transgene (red) and BrdU-labeled cells (green) in the SVZ (coronal section) $30 \mathrm{~d}$ after long-term exposure (10 mg/ml for 1 week in the drinking water). Inset, High magnification of an optical section $(0.5 \mu \mathrm{m})$ showing a large transgene-labeled SVZ cell $(\boldsymbol{A}$, box $)$ with as single process oriented away from the ventricle that is also labeled by BrdU $30 \mathrm{~d}$ after a long-term exposure. $\boldsymbol{B}-\boldsymbol{D}$, Examples of transgene-labeled SVZ cells that are also labeled after long-term BrdU exposure (yellow nuclei in cells with red processes and cytoplasm). $\boldsymbol{E}$, Thirty days after long-term exposure, several BrdU-labeled cells are scattered throughout the $C($ but, as shown in $A$, are rare in the SVZ. Inset, A long-term BrdU-labeled SVZ cell is clearly labeled for GFAP. F, Distribution of BrdU- and GFAP-labeled SVZ cells after acute BrdU exposure (2.5 h). The BrdU-labeled cells are more frequent. Inset, Most acutely labeled BrdU-positive cells do not express GFAP. G, Example of the $40 \times$ confocal maximum projection images used to estimate numbers of BrdU-labeled cells that express GFAP after acute exposure. $\boldsymbol{H}$, Quantitative estimate of the proportion of long-term versus acute BrdU-labeled cells that also express GFAP. Scale bars: $A, E, F, 200 \mu \mathrm{m} ; \boldsymbol{G}$, $25 \mu \mathrm{m}$; width of image in $\boldsymbol{B}, 50 \mu \mathrm{m}$; width of images in $C, D, 25 \mu \mathrm{m}$.

term versus acutely BrdU-labeled cells. Long-term BrdUlabeled cells (Fig. 5E) were far less frequent than acutely BrdUlabeled cells in the SVZ (Fig. 5F). Nevertheless, in the longterm labeled SVZ, GFAP/BrdU double-labeled cells were easily identifiable, whereas in the acutely labeled SVZ, the two populations were mostly distinct. We confirmed this impression by quantifying GFAP/BrdU double-labeled cells in confocal maximal projections (Fig. 5G). A greater percentage of BrdU-labeled cells coexpresses GFAP after long-term (65\%) versus acute BrdU exposure (11\%) (Fig. 5H). Thus, in addition to their molecular expression profile, transgene-labeled SVZ astrocytes have proliferative kinetics consistent with a subset of resident, slowly dividing neural precursors (see Fig. 9A).
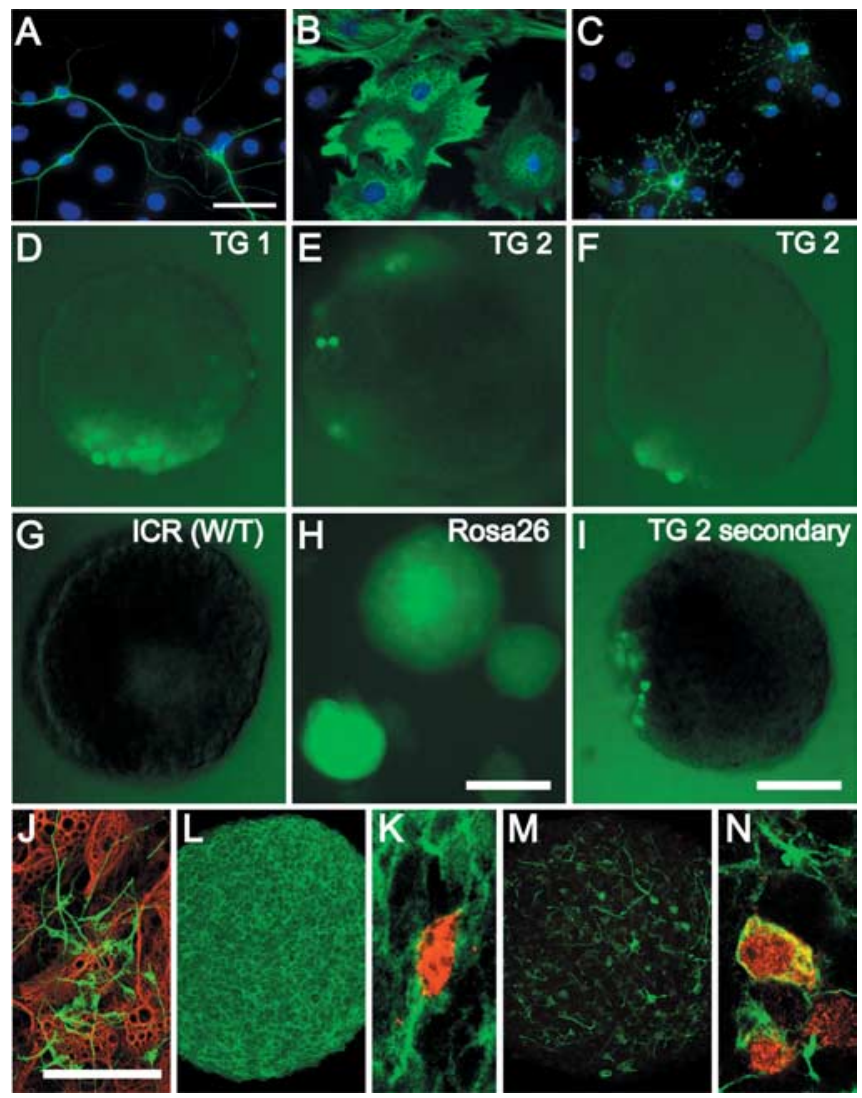

Figure 6. RA-activated cells can be recognized in a subset of SVZ-derived neurospheres. $\boldsymbol{A}-\boldsymbol{C}$, SVZ-derived neurospheres from adult DR5-RARE transgenic mice generate neurons $(\boldsymbol{A}$; TuJ1, green), astrocytes ( $\boldsymbol{B} ;$ GFAP, green), and oligodendrocytes ( $\boldsymbol{C} ; 04$, green) in the presence of serum. Nuclei, counterstained with bis-benzamide, are shown in blue. $\boldsymbol{D}-\boldsymbol{H}$, Live images of primary neurospheres derived from TG1 $(\boldsymbol{D})$, TG2 $(\boldsymbol{E}, \boldsymbol{F})$, ICR $(\boldsymbol{G})$, and Rosa-26 $(\boldsymbol{H})$ mice after incubation with CMFDG. I, TG2-derived secondary neurospheres have CMFDG-labeled cells, the distribution of which is similar to that in primary neurospheres. $J$, Individual primary neurospheres containing CMFDG transgene-labeled cells consistently produce neurons (TuJ1, green) and glia (GFAP, red) under differentiation conditions. $\boldsymbol{K}-\boldsymbol{N}$, Transgene-labeled cells retain expression of EGFR and GFAP in neurospheres. Confocal projections show EGFR $(\boldsymbol{K})$ and GFAP $(\boldsymbol{M})$ staining in intact, undifferentiated neurospheres. Transgene-labeled cells (red) express EGFR (green; $\boldsymbol{L}$ ) and GFAP (green; $\boldsymbol{N}$ ) in single $0.5 \mu \mathrm{m}$ optical sections through intact, undifferentiated neurospheres. Scale bars: $\boldsymbol{A}-\boldsymbol{C}, 100 \mu \mathrm{m} ; \boldsymbol{D}-\mathbf{G}, \boldsymbol{I}, 100 \mu \mathrm{m} ; \boldsymbol{H}, 200 \mu \mathrm{m} ; \boldsymbol{K}, \boldsymbol{M}, 100 \mu \mathrm{m}$; width of images in $L, N, 25 \mu \mathrm{m}$.

RA-activated cells can be identified in subsets of SVZ-derived neurospheres

If RA-activated SVZ cells are a consistent subset of proliferative neural precursors, they should be present in neurospheres, which are thought to represent clonally related SVZ precursors (Weiss et al., 1996). Primary SVZ-derived neurospheres from transgenic mice have the same capacity to generate neurons, astrocytes, and oligodendrocytes as their wild-type counterparts (Fig. 6A-C). In SVZ-derived neurospheres from TG mice, we identified small to prominent clusters of transgene-labeled cells using a fluorescent substrate for $\beta$-galactosidase, CMFDG (Fig. $6 D-F$ ). The percentage of primary neurospheres with RA-activated cells was consistent $(33 \%)$ in cultures generated from two independent lines of TG mice $(n=144$ TG1 spheres, $\mathrm{SEM}=2.8 ; n=178$ TG 2 spheres, $\mathrm{SEM}=3.8$ ). Fluorescent cells were not seen in non-TG neurospheres incubated with CMFDG (Fig. 6G). In contrast, fluorescence was seen throughout primary neurospheres from ROSA26 mice (Fig. $6 H$ ), which widely express $\beta$-galactosidase (Friedrich and Soriano, 1991; Zambrowicz et al., 1997), indicating that CM- 
FDG can penetrate neurospheres. Fluorescence was not uniform in ROSA26-derived neurospheres, perhaps reflecting the lack of expression of this transgene in astrocytes (Anthony et al., 2004). To determine whether similar populations of RA-activated cells are retained in clonally propagated neural precursors, we generated secondary neurospheres in which transgene-labeled cells are present in a proportion and pattern similar to that seen in primary neurospheres (Fig. 6I).

Individual primary neurospheres containing CMFDGlabeled RA-activated cells consistently produce neurons and glia (Fig. 6J); however, transgene-labeled cells were never detected in these differentiated cultures (data not shown). In undifferentiated neurospheres, transgene-labeled cells retain molecular characteristics seen in RA-activated SVZ cells in vivo. The EGFR is detected in most neurosphere cells, including those labeled by the transgene (Fig. $6 \mathrm{~K}, L$ ). GFAP is expressed by a much smaller subset (Fig. 6M), which includes all of the transgene-labeled neurosphere cells (Fig. $6 N)$ ( $n=26$ of 26 transgene-labeled cells). Thus, in SVZ-derived neurospheres, as in the SVZ, there is a subset of RA-activated, GFAP-expressing neural precursors.

\section{RA signaling in SVZ-derived neurospheres}

RA receptors, synthetic enzymes, and binding proteins are a minimal prerequisite for RA signaling in SVZ precursors. There is widespread expression of RAR $\alpha, \operatorname{RAR} \beta$, and RALDH3 in the SVZ (Fig. 7A-C), consistent with previous observations (Krezel et al., 1999; Wagner et al., 2002). This expression appears most intense along the lateral edge of the lateral ventricle, particularly in the dorsolateral arm. Transcripts for a wide range of RA receptors, binding proteins, and synthetic enzymes can be detected in the acutely dissected SVZ (Fig. 7D, top). There is a similar set of RA-signaling molecules in SVZ-derived neurospheres (Fig. 7D, bottom); however, RAR $\beta 4$, CRABP1, and RALDH2 are absent. $d l x 2$, a transcription factor expressed by transit-amplifying precursors, confirms SVZ and neurosphere identity, and $\beta$-galactosidase confirms transgene expression. Thus, overlapping subsets of RA receptors, binding proteins, and synthetic enzymes are available to support RA signaling in SVZ precursors in vivo as well as in vitro.

We next determined whether the transgene is specifically activated by RA in SVZ neural precursors in vitro and thus accurately reports active RA signaling. We incubated neurospheres with $100 \mathrm{nM}$ DEAB (Perz-Edwards et al., 2001), an RA synthesis inhibitor, for $4 \mathrm{~h}$ before the addition of CMFDG. Only a single, lightly fluorescent cell could be identified in $62 \mathrm{DEAB}$-treated neurospheres (Fig. 7E, panel $1)$. In contrast, clusters of fluorescent cells could be identified in untreated neurospheres processed in parallel (Fig. 7E, panel 2) or those coincubated with all-trans RA and DEAB (Fig. 7E, panel 3). To determine whether transgene activation in vitro depends on RA synthesis from its presumed in vivo premetabolite retinol, we grew neurospheres in retinol-free B27 medium and assayed CMFDG labeling. We harvested 83 neurospheres grown without retinol and identified no fluorescent cells (Fig. 7E, panel 4). Thus, RA signaling in TGderived neurospheres depends on RA synthesis, most likely from a retinol precursor.

We next assessed the capacity of dissociated SVZ cells cultured in the absence of retinol to form neurospheres. SVZ cells grown in retinol-free medium generate significantly fewer neurospheres (32\% of control) (i.e., a $68 \%$ reduction) (Fig. $7 F$ ); however, there is no significant difference in the size of the remaining neurospheres generated in retinol-free cultures ( $p \geq 0.3$; Mann-Whitney). If RA was necessary for survival of SVZ precursors that generate neurospheres, then one would expect to see a significant increase in dead cells in retinol-free cultures. Thus, we assessed cell viability in dissociated SVZ cells cultured either in control or retinol-free media throughout the standard period for neurosphere generation. There was no significant difference in the proportion of live to dead cells in the presence or absence of retinol (Fig. 7G). Thus, retinol, a primary RA premetabolite, may influence the ability of a subset of SVZ cells to form neurospheres; however, general toxicity or enhanced cell death as a result of RA deprivation is unlikely to explain this change.

\section{Influence of RA signaling on precursor proliferation}

The majority of precursors in neurospheres are thought to be transit-amplifying cells (Doetsch et al., 2002). Thus, if RA acts as a modulator of slowly dividing precursors, as suggested by our in vivo data, rather than a mitogen for transit-amplifying cells, one would not expect RA to enhance cell proliferation in early differentiating neurosphere cultures. To address this issue, we exposed adult SVZ-derived neurospheres to exogenous RA and analyzed BrdU incorporation. Acute exposure to either $10^{-6}$ or $10^{-7} \mathrm{M} \mathrm{RA}$ for $24 \mathrm{~h}$ before differentiation did not significantly alter the mitotic index of SVZ precursors (Fig. $7 H$ ). In contrast, exposure to $100 \mathrm{~nm}$ DEAB results in a significant increase in the proportion of BrdU-labeled cells ( $p \geq 0.006$; Mann-Whitney) (Fig. 7H). Thus, it is unlikely that RA elicits an acute and significant increase in cell proliferation from the transit-amplifying majority of neurosphere-derived cells. Instead, RA may modulate proliferative kinetics in a smaller subset of SVZ-derived precursors.

\section{RA signaling in a subpopulation of SVZ glial cells during development}

RA signaling in the adult forebrain occurs primarily in regions with embryonic forerunners that are sites of local RA-mediated induction (LaMantia et al., 1993; Whitesides et al., 1998; Haskell et al., 2002). We asked whether this regional coincidence is paralleled by RA activation in proliferative cells with glial characteristics in restricted domains of the developing ventral forebrain. We found RA-activated, RC2-labeled radial glial cells in the ventrolateral pallium and dLGE (Fig. $8 A-D$ ), embryonic areas that give rise to the adult SVZ (Merkle et al., 2004). RA receptors $\operatorname{RAR} \alpha$ and $\operatorname{RAR} \beta$ are expressed throughout the forebrain at this stage (Fig. $8 E, F$ ), and the RA synthetic enzyme RALDH3 is concentrated in the embryonic SVZ (Fig. 8G). RA-activated cells (Fig. $8 \mathrm{H}$ ) define a more discrete zone at the junction of the ventral pallium/ dLGE within the Pax6 domain of the neocortical rudiment (Fig. 8I) as well as the LGE-restricted Gsh2 domain (Fig. $8 J$ ). The zone of RA activation is most coincident with the ER81 domain associated with the dLGE region thought to generate OB granule cells (Fig. $8 \mathrm{~K}$ ) (Wichterle et al., 1999; Stenman et al., 2003).

We next evaluated the proliferative capacity of the RAactivated radial glial cells in vivo and in vitro. A substantial population of RA-activated radial cells is mitotically labeled after acute exposure to BrdU (Fig. $8 \mathrm{~L}$ ). The presence of RA-activated cells in primary neurospheres cultured from dissociated E14.5 ventral pallium/dLGE is consistent with their apparent precursor identity (Fig. $8 \mathrm{M}$ ). Moreover, RA-activated cells are not seen in differentiated neurons in glia in cultures from E14.5 neurospheres (data not shown). RA-activated cells persist in the ventral pallium/dLGE through at least P2 (Fig. $8 N$ ), when radial glia transform into mature SVZ astrocytes (Tramontin et al., 2003). At P2, these transgene-labeled cells coexpress the radial glial marker glial glutamate transporter (GLAST) and GFAP (Fig. 8OQ). Thus, subsets of RA-activated precursors with evolving glial characteristics are found consistently at similar sites (the SVZ and 

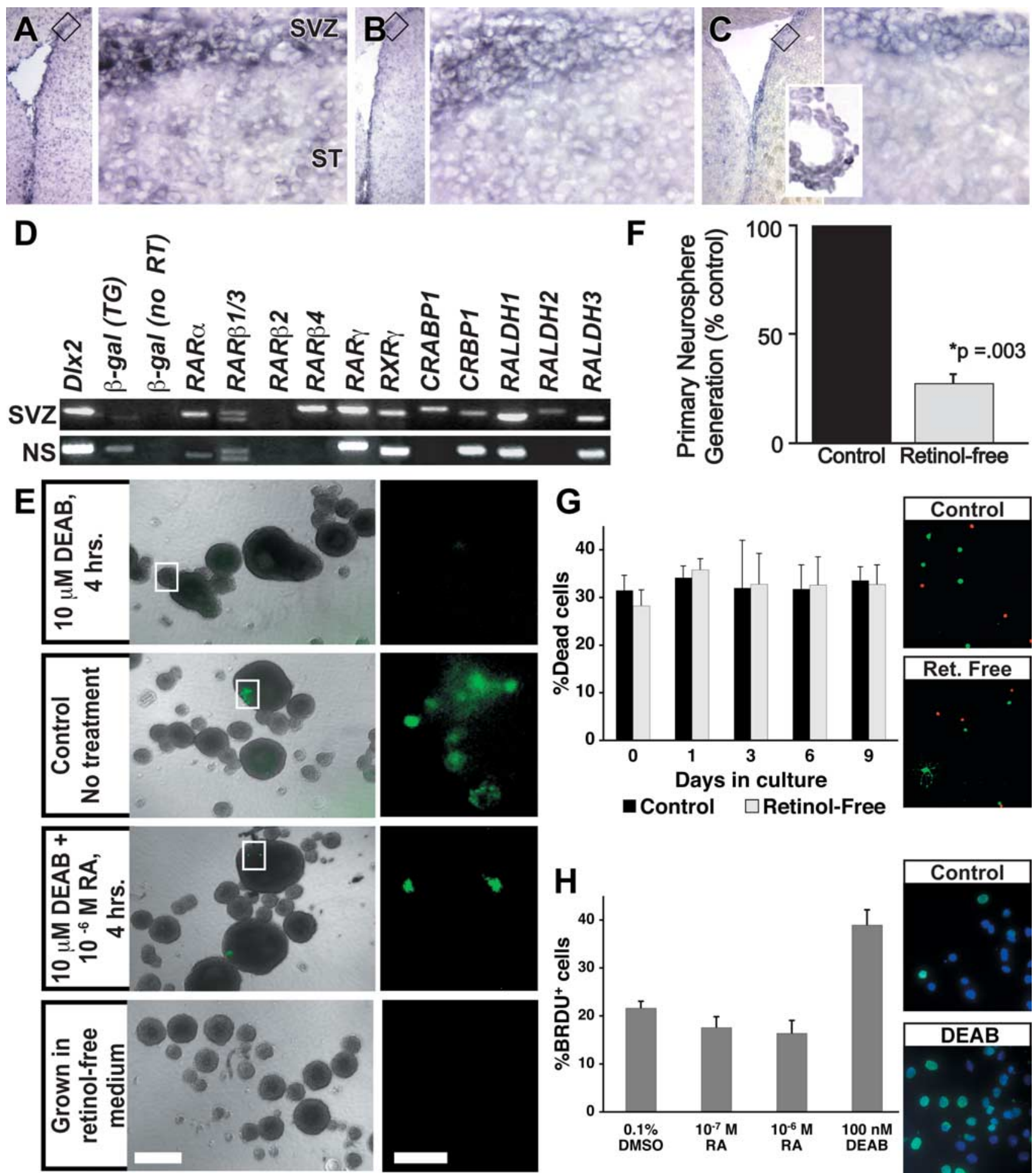

Figure 7. RA signaling in the SVZ and in SVZ-derived precursors. $A$, Left, RAR $\alpha$ mRNA can be detected in the ventricular region in a low-magnification image of the lateral ventricle. Right, RAR $\alpha$-expressing cells are concentrated in the SVZ and are detected at much lower intensity in the striatum (ST). $\boldsymbol{B}$, The distribution of RAR $\beta$ parallels that of RAR $\alpha$. C, RALDH3, an RA synthetic enzyme, is seen around the lateral ventricle, concentrated in the SVZ, as well as in the choroid plexus (inset). $\boldsymbol{D}$, RA-signaling molecules are expressed in acutely microdissected adult TG2 SVZ (top) and SVZ-derived primary neurospheres (bottom). RAR $\beta 4$, CRABP1, and RALDH2, which are expressed in the SVZ, are not detected in neurospheres. $\boldsymbol{E}$, Transgene activation in SVZ-derived neurospheres depends on RA, synthesized from retinol. Top, Transgene-expressing cells are virtually undetectable in TG neurospheres incubated for $4 \mathrm{~h}$ with DEAB, an RA synthesis inhibitor. Middle, Top, Control TG neurospheres processed in parallel contain transgene-expressing cells. Middle, Bottom, Transgene expression is restored in TG neurospheres coincubated with DEAB and RA $4 \mathrm{~h}$ before CMFDG incubation. Bottom, Transgene-expressing cells cannot be detected in TG neurospheres grown in the absence of retinol, the requisite metabolic precursor of RA. $\boldsymbol{F}$, The RA precursor retinol is necessary to generate normal numbers of SVZ-derived neurospheres in vitro. The histogram shows a comparison of numbers of primary neurospheres generated in retinol-free media compared with control. The error bar indicates SEM ( $n=9$ sets of control and retinol-free cultures). $G$, Absence of retinol does not induce cell death in SVZ cells. Left, The histogram indicates no difference in the proportions of live to dead SVZ cells cultured in control or retinol-free medium over the $9 \mathrm{~d}$ period of neurosphere generation. Right, Examples of live cells (green) and presumed dead cells (red) in the live/dead assay used to quantify cell viability during neurosphere generation. $\boldsymbol{H}$, RA modulates SVZ precursor proliferation in vitro. Left, The histogram illustrates the proportion of BrdU-labeled cells in adult SVZ neurospheres acutely exposed to either $10^{-6}$ or $10^{-7} \mathrm{M} \mathrm{RA}$ or $100 \mathrm{~nm} \mathrm{DEAB}$. Right, Examples of BrdU labeling in control (top) or DEAB-treated (bottom) differentiating cultures from neurospheres. Scale bars: $\boldsymbol{B}$, Left, $0.5 \mathrm{~mm}$; Right, $50 \mu \mathrm{m}$. 


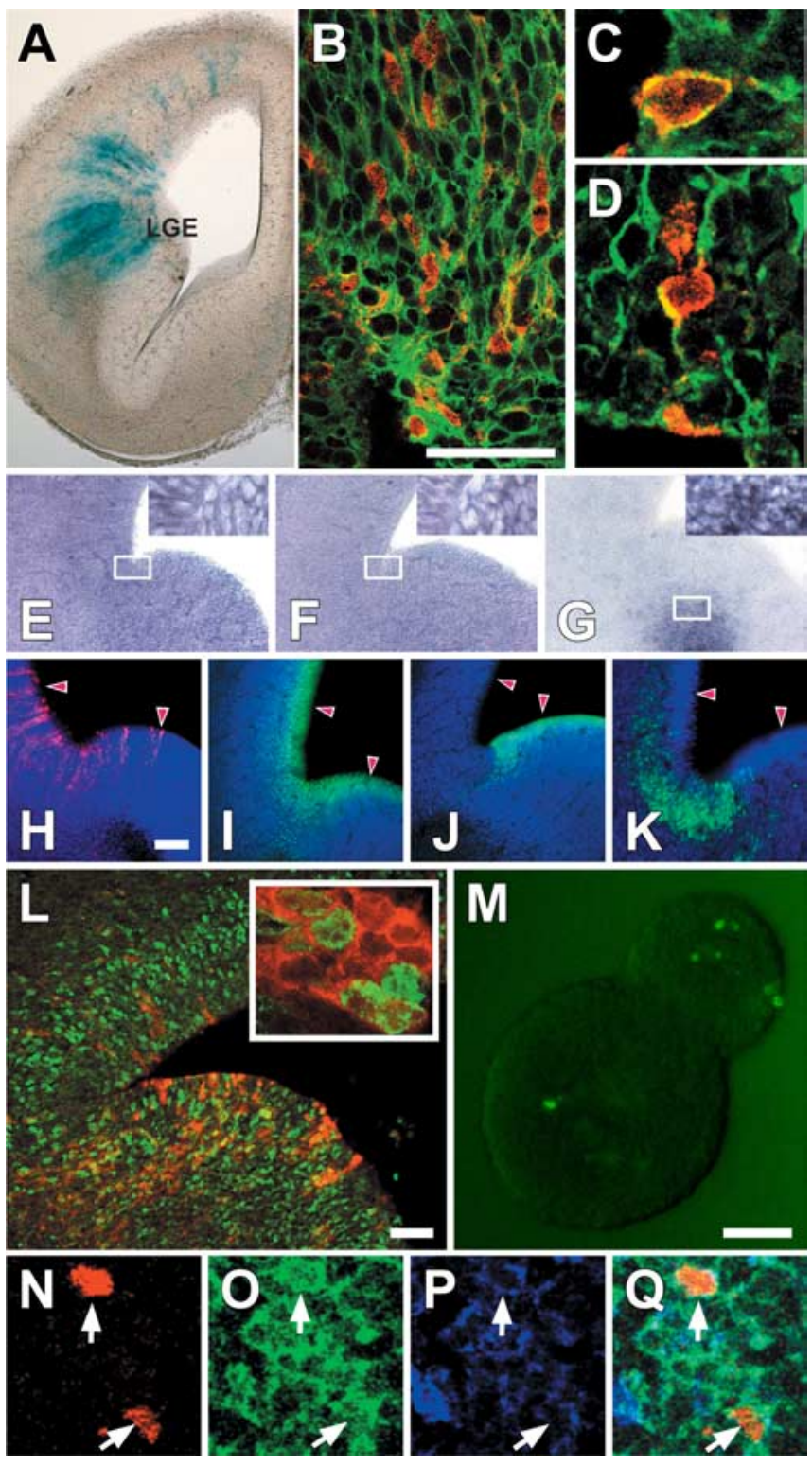

Figure 8. RA-activated, proliferative radial glia in embryonic brain regions that give rise to the SVZ as well as OB granule cells. $A$, Transgene-labeled, radial cells are seen in the dLGE as well as the lateral portion of the neocortical rudiment in the E14.5 forebrain. $\boldsymbol{B}$, Transgene-labeled cells constitute a subset of RC2-positive radial cells in the LGE. C, D, Colocalization of RC2 and the transgene is seen in individual cells in single optical sections $(0.5 \mu \mathrm{m}) . \boldsymbol{E}-\boldsymbol{G}, \operatorname{RAR} \alpha(\boldsymbol{E})$ and $\operatorname{RAR} \beta(\boldsymbol{F})$ are ubiquitously expressed in pallial as well as LGE cells, whereas RALDH3 $(\boldsymbol{G})$ is limited to the embryonic SVZ. The insets show that in labeled regions, every recognizable cell expressed the relevant mRNA. $\boldsymbol{H}-\boldsymbol{K}$, E14.5 RA-activated radial cells $(\boldsymbol{H})$ are located at the junction of the ventral pallium/dLGE that spans transcriptional domains defined by Pax6 $(\boldsymbol{I})$ and Gsh2 $(J)$. Transgene-labeled cells are most closely spatially associated with the expression domain of ER81 $(\boldsymbol{K})$, which has been associated with the region that gives rise to $O B$ granule cells. $L$, At E14.5, some transgene-labeled cells (red) are also BrdU labeled $1 \mathrm{~h}$ after a single injection of BrdU. Inset, A higher-power image of the section in $K$ showing BrdU labeling (green) of individual RA-activated cells (red). $\boldsymbol{M}$, Transgene-labeled cells are present in a subset of 14.5 neurospheres. $\boldsymbol{M}-\boldsymbol{P}$, Triple labeling for $\beta$-gal $(\boldsymbol{N})$, GLAST $(\boldsymbol{O})$, and GFAP $(\boldsymbol{P})$ at P2 $(\boldsymbol{Q}$; merged image). Scale bars: $\boldsymbol{B}, 50 \mu \mathrm{m} ; \boldsymbol{E}-\mathbf{G}, 250 \mu \mathrm{m} ; \boldsymbol{H}-\boldsymbol{J}, 100 \mu \mathrm{m} ; \boldsymbol{K}, 25 \mu \mathrm{m} ; \boldsymbol{L}, 100 \mu \mathrm{m} ; \boldsymbol{M}-\boldsymbol{P}, 30$ $\mu \mathrm{m}$; width of image in $C, 15 \mu \mathrm{m} ; \boldsymbol{D}, 20 \mu \mathrm{m}$.

its anatomical antecedent, the ventrolateral pallium/dLGE) in the adult and embryonic forebrain (Fig. 9B).

\section{Discussion}

We have shown for the first time that endogenous RA signaling via an identified transcriptional pathway distinguishes forebrain neural precursors. In the adult SVZ, RA activates a subset of GFAP-expressing, slowly dividing astrocytes. The cellular properties and RA sensitivity of adult SVZ-derived precursors in vitro reinforce the impression that retinoids act on a distinct glial population rather than transit-amplifying cells or their immediate neuronal progeny. In embryonic regions that prefigure the SVZ, there are also RA-responsive, mitotically active radial glial cells. Thus, adult as well as embryonic forebrain neural precursors may be added to the list of diverse precursor cells that include RA in their signaling repertoire. This RA signaling in distinct subsets of spatially coincident forebrain glia may establish or maintain neurogenic or proliferative properties of $\mathrm{OB}$ precursors throughout prenatal and postnatal life.

\section{Defining RA signaling in the SVZ}

We used a previously characterized RA reporter transgene (Balkan et al., 1992; Colbert et al., 1993, 1995; LaMantia et al., 1993; Haskell et al., 2002) and several independent markers to identify SVZ cells that respond to endogenous RA. This approach integrates the influence of multiple RA-signaling molecules that establish a distinct transcriptional state (via the DR5-RARE) as opposed to relying on the singular expression of any one RArelated factor to infer retinoid-mediated transcriptional activation. Thus, one can identify subsets of RA-activated cells in regions like the SVZ or developing forebrain, where RA signaling molecules are widely available. Several observations validate the specificity of this approach. RA-activated neural precursors have identical characteristics in two independent transgenic lines. Furthermore, transgene expression in SVZ-derived precursors in vitro is sensitive to the RA synthesis inhibitor DEAB and depends on the RA premetabolite retinol. Thus, this RA-responsive transgene, in the context of other markers, provides a specific, physiologically verifiable approach to selectively identify forebrain precursors that include a distinct RA-mediated transcriptional response among their cellular characteristics.

\section{Multiple roles for RA signaling}

We identified RA-activated granule cells in the adult OB; however, they are not new neurons. Instead, they are generated early, do not die in large numbers, and persist in the adult. It seems unlikely that these cells and the RA-activated SVZ precursors that we characterized are directly linearly related. Instead, there may be independent roles for RA at distinct olfactory sites: one associated with stable granule cells generated during early postnatal life and another with slowly proliferating SVZ glia. Altered RA signaling in vitro modulates a variety of cellular mechanisms in tissues from the prenatal or early postnatal olfactory pathway (Whitesides et al., 1998; Wang et al., 2005; Yee and Rawson, 2005), The specific activation by RA of the two cell classes identified here amplifies the conclusion that retinoids, via a range of transcriptional pathways including the DR5-RARE, may help to define cellular diversity in the olfactory pathway.

We did not detect RA-activated cells in the hippocampus despite ongoing neurogenesis in the subgranular zone, which is often compared with that in the SVZ. Recent reports suggest that exogenous RA influences hippocampal granule cell precursor proliferation (Crandall et al., 2004), and that changes in hippocampal plasticity accompany altered retinoid signaling (Chiang et al., 1998; Misner et al., 2001). RA signaling in the SVZ may have a distinct function from that in the hippocampus. SVZ precursors generate olfactory inhibitory interneurons, whereas their hippocampal counterparts generate primarily projection neurons (Seaberg and van der Kooy, 2002). In the adult, as in the 
A

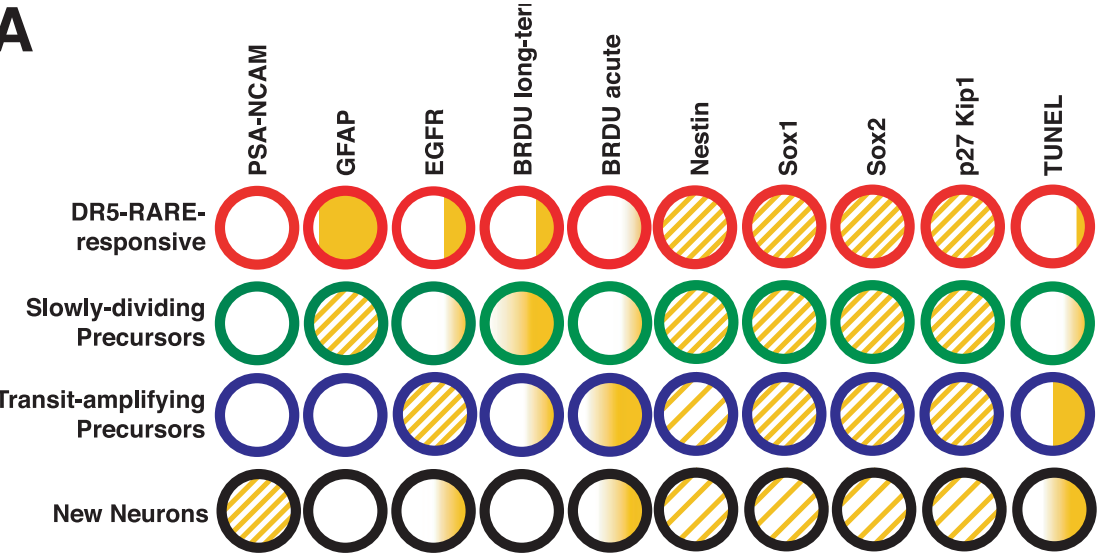

B
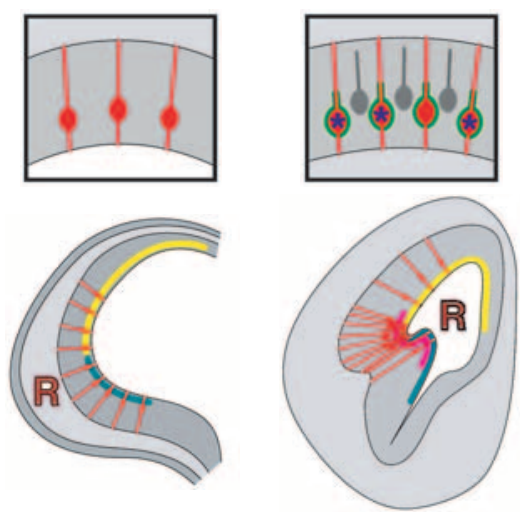

RA-Activated

Glial Markers

* Mitotically Labelled

R RA Source

Figure 9. A, DR5-RARE/RA-activated astrocytes are a subset of resident, slowly dividing SVZ neural precursors. Our observations are summarized graphically in the first row; those in the subsequent rows are a synthesis of our observations and those of several other investigators defining distinct SVZ cell classes. Solid yellow indicates that a percentage of colocalization has been quantified. Graded yellow indicates ambiguity as a result of no data on colocalization of relevant markers. Hatching represents expression presumed to occur throughout the population indicated; however, the coincidence of these and other labels, including the transgene, has not been quantified. Hatching density is proportional to levels of expression. $\boldsymbol{B}, \mathrm{RA}$-activated cells with radial glial or astrocytic properties are found at a consistent site in the developing and adult forebrain. Initially (E9.5-E10.5), these cells occupy a subdomain of the ventrolateral prosencephalon overlapping both the Pax6 and Gsh2 transcriptional domains. Subsequently (E14.5), proliferative RA-activated radial glial cells are seen in a similar region, now identified as the ventral pallium/dLGE, in register with the Er81 transcriptional domain. At P2, RA-activated glial cells make a transition from embryonic radial cells to mature astrocytes in the incipient SVZ, and they become less frequent. In the adult, a small population of RA activated, slowly dividing, GFAP-expressing precursors remain in the SVZ, thus maintaining the continuity of RA-activated cells in this region throughout life.

embryo, transgene-labeled cells are restricted to regions associated with genesis of GABAergic interneurons, including the rudimentary OB and SVZ as well as lamina 2 of the spinal cord dorsal horn (Haskell et al., 2002). Our results reinforce the idea that RA signaling distinguishes "intermediate" telencephalic precursors (Marklund et al., 2004) associated with giving rise to olfactory, amygdalar, or striatal neurons. Thus, DR5-RAREmediated RA signaling may be particularly important for genesis or maintenance of inhibitory interneurons in the $\mathrm{OB}$ and other selected sites, especially those that rely on RA signaling during early development.
DR5-RARE/RA-activated cells are slowly dividing, resident $S V Z$ precursors

A majority of RA-activated SVZ cells express GFAP, the primary marker associated with slowly dividing neural precursors, which may include a population of adult neural stem cells (Fig. 9A) (Doetsch et al., 1999b; Palmer et al., 2000; Morshead et al., 2003; Shen et al., 2004). This quantitative confocal analysis corrects our initial impression, based on epifluorescence microscopy, that RA-activated cells were not labeled by GFAP (Haskell et al., 2002). The mitotic profile of RA-activated cells, recognized by long-term BrdU exposure, associates them most securely with resident, slowly dividing neural precursors. Nevertheless, the lack of specific markers beyond GFAP, nestin, Soxl, and Sox2 (all of which are expressed in RAactivated cells) makes it impossible to assign an identity beyond neural precursor to the RA-activated cells described here. A subset of RA-activated cells (23\%) also expresses the EGFR, which has been associated with SVZ precursor proliferation in vitro and in vivo (Tropepe et al., 1997). At least some RAactivated cells, including $4 \%$ that do not express GFAP, may respond to this mitogen, perhaps during a transition from quiescent to mitotically active, fate-restricted precursors (Doetsch et al., 2002). Neither our in vivo nor our in vitro observations can resolve whether the RA-activated cells characterized here have additional stem cell properties; nevertheless, our data establishes that RA signaling distinguishes a subset of resident slowly dividing neural precursors in the adult SVZ.

\section{Role of RA signaling in SVZ precursors}

We used neurospheres, which recapitulate several features of the SVZ, to further evaluate RA signaling in forebrain-derived precursors. RA signaling characterizes a small but consistent subset of GFAPpositive precursors in vitro as in vivo, and loss of transgene activation after inhibiting RA synthesis indicates that these cells are actively responding to RA. We cannot comment on the relationship between neurospheres containing RA-activated cells and potential RA-activated founders from the SVZ. Nevertheless, it is clear that RA signaling establishes cellular diversity among precursors propagated in vitro, perhaps reflecting similar diversity in the SVZ in vivo. The absence of transgene labeling in neurons or glia differentiated from neurospheres reinforces our in vivo observation that DR5-RAREmediated RA activation is not associated with newly generated neurons or differentiated glia.

The acute effects of pharmacological loss and gain of function indicate that RA may stabilize or modestly diminish, rather than enhance, neurosphere precursor proliferation. These in vitro data, in accord with our in vivo data, indicate that RA does not act 
as a proliferative signal for transit-amplifying cells via DR5RARE-dependent transcriptional pathways (Fig. 9A). Endogenous, locally available RA may regulate neural precursors with broader potential or sustained mitotic capacity without acutely eliciting cell death or proliferation (Morshead et al., 2002), perhaps in 33\% of neurospheres that include transgene-labeled cells rather than $70 \%$ thought to derive from transit-amplifying precursors (Doetsch et al., 2002). RA signaling may establish a complex transcriptional state in combination with several other molecular determinants (beyond a specific group of retinoid receptors or cofactors, including the subset examined here) to influence precursor identity or differentiation (Cheng et al., 2005). Resolution of this question will require better tools for sorting and identifying single RA-activated cells from the SVZ for clonal analysis in response to a variety of RA-signaling conditions.

\section{Continuity of RA signaling in the developing and adult forebrain}

RA signaling distinguishes precursors with overlapping cellular characteristics in the ventricular region of the ventrolateral forebrain throughout life. Such cells may be specified as early as E9.5, when RA from the frontonasal mesenchyme activates RA signaling in adjacent neuroepithelial cells located in the ventrolateral forebrain (Fig. 9B) (LaMantia et al., 1993, 2000; Anchan et al., 1997). It is not clear whether these cells and, subsequently, RAactivated radial glial cells are linearly related to adult SVZ astrocytes (Alvarez-Buylla et al., 2001; Gotz, 2003; Anthony et al., 2004). Changes in early transcription factor expression that coincides with the RA-activated region of the ventral forebrain, including Pax6, Gsh2, and ER81, as well as distinct proliferative kinetics in a developing versus regenerating neuroepithelium, may set different contexts for DR5-RARE-mediated RA signaling. Nevertheless, the spatial coincidence as well as shared cellular properties of RA-activated cells in the ventral prosencephalon, ventral pallium/dLGE, and adult SVZ suggests that related subpopulations of forebrain precursors may be further specified by endogenous, local RA signaling throughout life, especially in forebrain regions associated with the initial genesis or subsequent replacement of olfactory bulb interneurons.

\section{References}

Allen SP, Maden M, Price JS (2002) A role for retinoic acid in regulating the regeneration of deer antlers. Dev Biol 251:409-423.

Alvarez-Buylla A, Garcia-Verdugo JM, Tramontin AD (2001) A unified hypothesis on the lineage of neural stem cells. Nat Rev Neurosci 2:287-293.

Anchan RM, Drake DP, Haines CF, Gerwe EA, LaMantia AS (1997) Disruption of local retinoid-mediated gene expression accompanies abnormal development in the mammalian olfactory pathway. J Comp Neurol 379:171-184.

Anthony TE, Klein C, Fishell G, Heintz N (2004) Radial glia serve as neuronal progenitors in all regions of the central nervous system. Neuron 41:881-890.

Balkan W, Colbert M, Bock C, Linney E (1992) Transgenic indicator mice for studying activated retinoic acid receptors during development. Proc Natl Acad Sci USA 89:3347-3351.

Bastien J, Rochette-Egly C (2004) Nuclear retinoid receptors and the transcription of retinoid-target genes. Gene 328:1-16.

Bickenbach JR, Chism E (1998) Selection and extended growth of murine epidermal stem cells in culture. Exp Cell Res 244:184-195.

Cheng LC, Tavazoie M, Doetsch F (2005) Stem cells from epigeneticsto microRNAs. Neuron 46:363-367.

Chiang MY, Misner D, Kempermann G, Schikorski T, Giguere V, Sucov HM, Gage FH, Stevens CF, Evans RM (1998) An essential role for retinoid receptors RARbeta and RXRgamma in long-term potentiation and depression. Neuron 21:1353-1361.
Colbert MC, Linney E, LaMantia AS (1993) Local sources of retinoic acid coincide with retinoid-mediated transgene activity during embryonic development. Proc Natl Acad Sci USA 90:6572-6576.

Colbert MC, Rubin WW, Linney E, LaMantia AS (1995) Retinoid signaling and the generation of regional and cellular diversity in the embryonic mouse spinal cord. Dev Dyn 204:1-12.

Crandall J, Sakai Y, Zhang J, Koul O, Mineur Y, Crusio WE, McCaffery P (2004) 13-Cis-retinoic acid suppresses hippocampal cell division and hippocampal-dependent learning in mice. Proc Natl Acad Sci USA 101:5111-5116.

Denisenko-Nehrbass NI, Jarvis E, Scharff C, Nottebohm F, Mello CV (2000) Site-specific retinoic acid production in the brain of adult songbirds. Neuron 27:359-370.

Dirks PB, Patel K, Hubbard SL, Ackerley C, Hamel PA, Rutka JT (1997) Retinoic acid and the cyclin dependent kinase inhibitors synergistically alter proliferation and morphology of U343 astrocytoma cells. Oncogene 15:2037-2048.

Doetsch F, Garcia-Verdugo JM, Alvarez-Buylla A (1999a) Regeneration of a germinal layer in the adult mammalian brain. Proc Natl Acad Sci USA 96:11619-11624.

Doetsch F, Caille I, Lim DA, Garcia-Verdugo JM, Alvarez-Buylla A (1999b) Subventricular zone astrocytes are neural stem cells in the adult mammalian brain. Cell 97:703-716.

Doetsch F, Petreanu L, Caille I, Garcia-Verdugo JM, Alvarez-Buylla A (2002) EGF converts transit-amplifying neurogenic precursors in the adult brain into multipotent stem cells. Neuron 36:1021-1034.

Fiske BK, Brunjes PC (2001) Cell death in the developing and sensorydeprived rat olfactory bulb. J Comp Neurol 431:311-319.

Friedrich G, Soriano P (1991) Promoter traps in embryonic stem cells: a genetic screen to identify and mutate developmental genes in mice. Genes Dev 5:1513-1523.

Garcia AD, Doan NB, Imura T, Bush TG, Sofroniew MV (2004) GFAPexpressing progenitors are the principal source of constitutive neurogenesis in adult mouse forebrain. Nat Neurosci 7:1233-1241.

Giardino L, Bettelli C, Calza L (2000) In vivo regulation of precursor cells in the subventricular zone of adult rat brain by thyroid hormone and retinoids. Neurosci Lett 295:17-20.

Gotz M (2003) Glial cells generate neurons-master control within CNS regions: developmental perspectives on neural stem cells. Neuroscientist 9:379-397.

Haskell GT, Maynard TM, Shatzmiller RA, Lamantia AS (2002) Retinoic acid signaling at sites of plasticity in the mature central nervous system. J Comp Neurol 452:228-241.

Herbert J, Wilcox JN, Pham KT, Fremeau Jr RT, Zeviani M, Dwork A, Soprano DR, Makover A, Goodman DS, Zimmerman EA (1986) Transthyretin: a choroid plexus-specific transport protein in human brain. The 1986 S. Weir Mitchell Award. Neurology 36:900-911.

Hind M, Maden M (2004) Retinoic acid induces alveolar regeneration in the adult mouse lung. Eur Respir J 23:20-27.

Hinds JW (1968) Autoradiographic study of histogenesis in the mouse olfactory bulb. I. Time of origin of neurons and neuroglia. J Comp Neurol 134:287-304.

Imai T, Jiang M, Kastner P, Chambon P, Metzger D (2001) Selective ablation of retinoid $\mathrm{X}$ receptor alpha in hepatocytes impairs their lifespan and regenerative capacity. Proc Natl Acad Sci USA 98:4581-4586.

Krezel W, Kastner P, Chambon P (1999) Differential expression of retinoid receptors in the adult mouse central nervous system. Neuroscience 89:1291-1300.

LaMantia AS, Colbert MC, Linney E (1993) Retinoic acid induction and regional differentiation prefigure olfactory pathway formation in the mammalian forebrain. Neuron 10:1035-1048.

LaMantia AS, Bhasin N, Rhodes K, Heemskerk J (2000) Mesenchymal/epithelial induction mediates olfactory pathway formation. Neuron 28:411-425.

Legrier ME, Ducray A, Propper A, Chao M, Kastner A (2001) Cell cycle regulation during mouse olfactory neurogenesis. Cell Growth Differ 12:591-601.

Lutzow-Holm C, De Angelis P, Clausen OP (1992) Retinoic acid provokes a regeneration-like proliferative response in murine epidermis. A bivariate DNA/bromodeoxyuridine flow cytometric study. Arch Dermatol Res 284:418-423.

Marklund M, Sjodal M, Beehler BC, Jessell TM, Edlund T, Gunhaga L (2004) 
Retinoic acid signalling specifies intermediate character in the developing telencephalon. Development 131:4323-4332.

Merkle FT, Tramontin AD, Garcia-Verdugo JM, Alvarez-Buylla A (2004) Radial glia give rise to adult neural stem cells in the subventricular zone. Proc Natl Acad Sci USA 101:17528-17532.

Mic FA, Molotkov A, Molotkov N, Duester G (2004) Raldh2 expression in optic vesicle generates a retinoic acid signal needed for invagination of retina during optic cup formation. Dev Dyn 231:270-277.

Misner DL, Jacobs S, Shimizu Y, de Urquiza AM, Solomin L, Perlmann T, De Luca LM, Stevens CF, Evans RM (2001) Vitamin A deprivation results in reversible loss of hippocampal long-term synaptic plasticity. Proc Natl Acad Sci USA 98:11714-11719.

Morshead CM, Reynolds BA, Craig CG, McBurney MW, Staines WA, Morassutti D, Weiss S, van der Kooy D (1994) Neural stem cells in the adult mammalian forebrain: a relatively quiescent subpopulation of subependymal cells. Neuron 13:1071-1082.

Morshead CM, Craig CG, van der Kooy D (1998) In vivo clonal analyses reveal the properties of endogenous neural stem cell proliferation in the adult mammalian forebrain. Development 125:2251-2261.

Morshead CM, Benveniste P, Iscove NN, van der Kooy D (2002) Hematopoietic competence is a rare property of neural stem cells that may depend on genetic and epigenetic alterations. Nat Med 8:268-273.

Morshead CM, Garcia AD, Sofroniew MV, van Der Kooy D (2003) The ablation of glial fibrillary acidic protein-positive cells from the adult central nervous system results in the loss of forebrain neural stem cells but not retinal stem cells. Eur J Neurosci 18:76-84.

Nakatsuji Y, Miller RH (2001) Density dependent modulation of cell cycle protein expression in astrocytes. J Neurosci Res 66:487-496.

Otteson DC, D'Costa AR, Hitchcock PF (2001) Putative stem cells and the lineage of rod photoreceptors in the mature retina of the goldfish. Dev Biol 232:62-76.

Palmer TD, Willhoite AR, Gage FH (2000) Vascular niche for adult hippocampal neurogenesis. J Comp Neurol 425:479-494.

Perz-Edwards A, Hardison NL, Linney E (2001) Retinoic acid-mediated gene expression in transgenic reporter zebrafish. Dev Biol 229:89-101.

Pevny L, Rao MS (2003) The stem-cell menagerie. Trends Neurosci 26:351-359.

Rubin WW, LaMantia AS (1999) Age-dependent retinoic acid regulation of gene expression distinguishes the cervical, thoracic, lumbar, and sacral spinal cord regions during development. Dev Neurosci 21:113-125.

Saito K, Saito S, Taniguchi K, Kobayashi N, Terashita T, Shimokawa T, Mominoki K, Miyawaki K, Chen J, Gao SY, Li CY, Matsuda S (2004) Transient increase of TUNEL-positive cells on postnatal day 20 in the developing rat olfactory bulb. Neurosci Res 50:219-225.

Seaberg RM, van der Kooy D (2002) Adult rodent neurogenic regions: the ventricular subependyma contains neural stem cells, but the dentate gyrus contains restricted progenitors. J Neurosci 22:1784-1793.

Shen Q, Goderie SK, Jin L, Karanth N, Sun Y, Abramova N, Vincent P,
Pumiglia K, Temple S (2004) Endothelial cells stimulate self-renewal and expand neurogenesis of neural stem cells. Science 304:1338-1340.

Smith D, Wagner E, Koul O, McCaffery P, Drager UC (2001) Retinoic acid synthesis for the developing telencephalon. Cereb Cortex 11:894-905.

Stenman J, Toresson H, Campbell K (2003) Identification of two distinct progenitor populations in the lateral ganglionic eminence: implications for striatal and olfactory bulb neurogenesis. J Neurosci 23:167-174.

Thomaidou D, Mione MC, Cavanagh JF, Parnavelas JG (1997) Apoptosis and its relation to the cell cycle in the developing cerebral cortex. J Neurosci 17:1075-1085.

Tramontin AD, Garcia-Verdugo JM, Lim DA, Alvarez-Buylla A (2003) Postnatal development of radial glia and the ventricular zone (VZ): a continuum of the neural stem cell compartment. Cereb Cortex 13:580-587.

Tropepe V, Craig CG, Morshead CM, van der Kooy D (1997) Transforming growth factor- $\alpha$ null and senescent mice show decreased neural progenitor cell proliferation in the forebrain subependyma. J Neurosci 17:7850-7859.

Tsonis PA, Trombley MT, Rowland T, Chandraratna RA, del Rio-Tsonis K (2000) Role of retinoic acid in lens regeneration. Dev Dyn 219:588-593.

Tsonis PA, Tsavaris M, Call MK, Chandraratna RA, Del Rio-Tsonis K (2002) Expression and role of retinoic acid receptor alpha in lens regeneration. Dev Growth Differ 44:391-394.

Wagner E, Luo T, Drager UC (2002) Retinoic acid synthesis in the postnatal mouse brain marks distinct developmental stages and functional systems. Cereb Cortex 12:1244-1253.

Wang TW, Zhang H, Parent JM (2005) Retinoic acid regulates postnatal neurogenesis in the murine subventricular zone-olfactory bulb pathway. Development 132:2721-2732.

Weiss S, Dunne C, Hewson J, Wohl C, Wheatley M, Peterson AC, Reynolds BA (1996) Multipotent CNS stem cells are present in the adult mammalian spinal cord and ventricular neuroaxis. J Neurosci 16:7599-7609.

Whitesides J, Hall M, Anchan R, LaMantia AS (1998) Retinoid signaling distinguishes a subpopulation of olfactory receptor neurons in the developing and adult mouse. J Comp Neurol 394:445-461.

Wichterle H, Garcia-Verdugo JM, Herrera DG, Alvarez-Buylla A (1999) Young neurons from medial ganglionic eminence disperse in adult and embryonic brain. Nat Neurosci 2:461-466.

Yamamoto M, McCaffery P, Drager UC (1996) Influence of the choroid plexus on cerebellar development: analysis of retinoic acid synthesis. Brain Res Dev Brain Res 93:182-190.

Yee KK, Rawson NE (2005) Immunolocalization of retinoic acid receptors in the mammalian olfactory system and the effects of olfactory denervation on receptor distribution. Neuroscience 131:733-743.

Zambrowicz BP, Imamoto A, Fiering S, Herzenberg LA, Kerr WG, Soriano P (1997) Disruption of overlapping transcripts in the ROSA beta geo 26 gene trap strain leads to widespread expression of beta-galactosidase in mouse embryos and hematopoietic cells. Proc Natl Acad Sci USA 94: 3789-3794 